
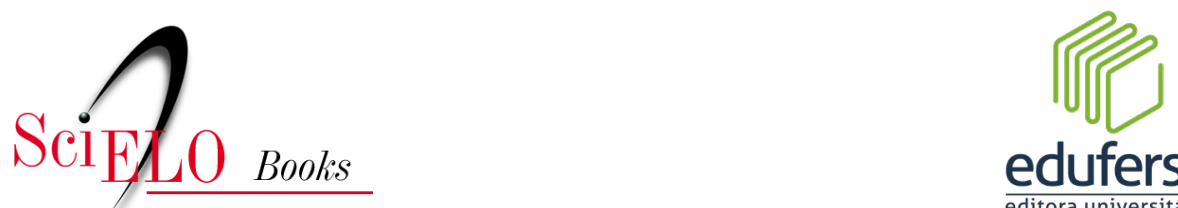

\title{
Parte II - História e Sociedade 7 - Tempestade Comunista: o jornal A Ordem e a escalada repressiva pós-1935
}

\author{
Micarla Natana Lopes Rebouças
}

\section{SciELO Books / SciELO Livros / SciELO Libros}

REBOUÇAS, M. N. L. Tempestade Comunista: o jornal A Ordem e a escaladarepressiva pós-1935. In: OLIVEIRA, A. M., SILVA, L. R., and FALCÃO, M. L., eds. Sociedade e cultura no Rio Grande do Norte: diálogos interdisciplinares [online]. Mossoró: EdUFERSA, 2021, pp. 137-155. ISBN: 978-65-87108-24-7. https://doi.org/10.7476/9786587108582.0008.

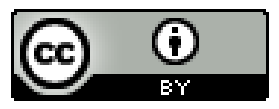

All the contents of this work, except where otherwise noted, is licensed under a Creative Commons Attribution 4.0 International license.

Todo o conteúdo deste trabalho, exceto quando houver ressalva, é publicado sob a licença Creative Commons Atribição 4.0.

Todo el contenido de esta obra, excepto donde se indique lo contrario, está bajo licencia de la licencia Creative Commons Reconocimento 4.0. 


\title{
7 || TEMPESTADE COMUNISTA: \\ O JORNAL A ORDEM E A ESCALADA REPRESSIVA Pós-1935
}

\author{
Micarla Natana Lopes Rebouças
}

A cidade de $\mathrm{Natal}^{53}{ }^{53}$ e aproximadamente 40 mil habitantes, assistiu, na noite de 23 de novembro de 1935, a concretização de um dos maiores temores católicos: uma experiência comunista em terras brasileiras. O som dos disparos que saía do $21^{\circ}$ Batalhão de Caçadores, naquela noite, quebrara a normalidade do sábado, embora somente na manhã seguinte seus habitantes e as próprias autoridade locais viriam a saber o que de fato havia ocorrido e as suas reais proporções. $\mathrm{O}$ tão temido "golpe extremista" havia sido dado, e a cidade amanhecia como palco do "primeiro ato da tragédia" (COSTA, 1995).

Não é difícil mensurar o quanto esse cenário se mostrou perturbador para hierarquia católica, naquele momento. Na edição de 01 de dezembro de 1935, o jornal A Ordem se referiu aos levantes como

53 Segundo Homero Costa, a Natal dos anos de 1930 apresentava-se como uma pequena cidade. Seus principais bairros eram a Ribeira, onde se concentrava o movimento comercial e artístico, contando com o Teatro Carlos Gomes, e a Cidade Alta, onde se situava o $21^{\circ}$ Batalhão de Caçadores. Havia, também, a Polícia Militar e Guarda Civil. O transporte público era feito através de bonde elétrico, e a cidade contava com a circulação de quatro jornais: A República (órgão oficial do governo); A Razão (ligado ao Partido Popular), A Ordem e O Jornal (ligado a Café Filho). Cf. Costa (1995, p. 81). 
uma tempestade de gravíssimas proporções. Passageira, devastadora, mas não inesperada, a "Intentona Comunista" foi exposta como uma tragédia anunciada, um desfecho previsível em meio aos presságios que haviam sido diuturnamente denunciados nas páginas do veículo católico.

Para o A Ordem, os acontecimentos de novembro não poderiam ser encarados como "uma simples quartelada", mas sim, como "puro comunismo" (AINDA..., 1935, p. 01). Interessava, pois, naquele momento, caracterizar o movimento como essencialmente comunista, fruto da ação subversiva da ANL sob a coordenação da Terceira Internacional, uma conspiração cuidadosamente orquestrada e organizada pelos extremistas sobre a qual haveria o jornal premunido os leitores. Esse interesse, por sua vez, seria partilhado pelo governo tanto na esfera estadual, como federal.

Como assinala Motta (2002), não se pode interpretar como fantasiosas as versões conservadoras que qualificaram e (denunciaram) o episódio de 1935 como tentativa comunista de assalto ao poder. Pois, de fato, são inegáveis as evidências de que se gestava um levante de grandes proporções, no Brasil. Entretanto, como defende o autor, pode-se questionar o conteúdo das representações anticomunistas construídas sobre o evento e o arsenal que as forças conservadoras lançaram mão na manipulação dos acontecimentos envolvidos na "Intentona Comunista" e o seu potencial estratégico para a causa anticomunista.

Nesse sentido, a experiência do levante, em Natal, abriu um terreno valioso para que se referendasse todo o conjunto imagético constituído ao redor da ameaça soviética e dos seus planos subversivos, no Brasil, sob o comando da ANL. Ao fornecer argumentos contundentes em torno do "perigo vermelho", os acontecimentos de novembro permitiram que a ofensiva católica tornasse as demandas anticomunistas irrevogáveis.

Potencializam-se os mecanismos de produção do medo que fizeram com que o discurso preventivo dos primeiros meses de 1935 desse lugar ao discurso prescritivo que marca as investidas anticomunistas pós-levantes, amparado, sobretudo, nas propostas em torno da chamada 
"profilaxia social". A partir dessa perspectiva, entendia-se que, assim como o funcionamento do organismo, pautado na coordenação entre as partes que o compõe, a sociedade, enquanto uma vasta organização que comporta uma rede de micro-organizações (família, escola, Estado, partido, Igreja), necessitaria da harmonização entre esses elementos. O orgânico pressupõe, portanto, "uma sociedade unitária e uma vida política harmoniosa", e sua subversão representaria o perecimento de todo o corpo social. (DUTRA, 2012, p. 49).

Os impactos da tempestade e o cenário de desordem por ela deixados, portanto, foram providenciais para a consolidação do imaginário anticomunista nas páginas do A Ordem, mas, mais do que isso, abriram espaço para que a Igreja demarcasse seu lugar nas disputas políticos-ideológicas, utilizando-se do "perigo vermelho" "como uma ameaça que lhes cabe enfrentar em nome da sociedade como um todo" (RODEGHERO, 2002, p. 465).

É a partir desse panorama de montagem das frentes de combate ao comunismo pós-levantes, que este artigo tem como objetivo analisar os impactos da chamada "Intentona Comunista" na composição do imaginário anticomunista, perscrutando como a imprensa católica, mais especificamente o jornal A Ordem, explorou as ressonâncias do Levante, em Natal, como importante elemento de coesão das forças católicas em torno do inimigo, tornando indissociáveis o recrudescimento das batalhas anticomunistas e a defesa do projeto recatolizador da sociedade.

\section{1 “A tempestade passou, graças a Deus!"}

Na edição de 01 de dezembro de 1935, número que marca o retorno do A Ordem, após uma semana de interrupção, ${ }^{54}$ o jornal enaltece aos que combateram contra o comunismo e defenderam "as tradições christãs":

54 De 24 a 27 de novembro de 1935, período de que data a ação comunista no estado, a redação do periódico foi ocupada pelos revolucionários, que ironicamente transformaram o veículo católico em órgão ligado a 
Não podemos regatear o nosso applauso a todos aquelles, civis e militares que souberam defender dignamente as nossas tradições christãs, enfrentando com denodo o golpe extremista. Aos dignos officiaes, inferiores e praças da Polícia Militar e do $21^{\circ}$ B.C., fieis da legalidade as familias christãs do Rio Grande do Norte asseguram a sua maior gratidão. Digna dos maiores encomios foi a valentia dos nossos sertanejos, que marcharam contra a invasão communista, animados pelos seus chefes e pelos sacerdotes das parochias do interior. Aos que tombaram na lucta pela defesa da civilização christã, Deus saberá premia-los como merecem (O FRACASSO..., 1935, p. 01).

A mesma edição traz importantes referências para que se percebam os principais arranjos que compuseram a produção do discurso anticomunista a partir daquele momento. O jornal procurou demonstrar que, diante da concretização dos temores católicos, "aos tibios e aos comodistas" (A Ordem, $01 \mathrm{dez}$ 1935, p.1), era preciso deixar claro que o perigo a que muitos julgavam retórico, havia se tornado uma ameaça concreta e, que diante dessa "tremenda provocação", caberia aos "catholicos conscientes e patriotas sinceros" restaurar a civilização cristã da "barbaria materialista".

Nesse sentido, no calor da hora, o jornal se esforçou para que os leitores encarassem os eventos do final de novembro como um ultraje à civilização cristã, sendo essa afronta simbolizada pela "ousadia" dos comunistas em ocupar a redação do único veículo católico do estado, o que, para o jornal, seria uma tentativa de "humilhar" a "população catholica do Estado". Para os editores do A Ordem:

Os comunistas tiveram a ousadia de transformar esta folha em órgão da 'Alliança Nacional Libertadora', pretendendo humilhar a população catholica do Estado, que viu o seu jornal transformado, de momento para o outro, em centro de irradiação vermelha.

“Aliança Nacional Libertadora”. Na ocasião, os revolucionários destruíram a tiragem dominical e prenderam os funcionários do jornal. 
Aquelle typos e aquellas machinas, sempre por nós utilizados em defesa de Jesus Christo e de sua Igreja passaram a ser cinicamente empregados pelos agentes de Moscou, em propaganda do anti-christo e da lepra marxista, contra os quaes sempre tivemos assestadas nossas baterias.

Os invasores queimaram nossa edição de domingo que trazia o EVANGELHO de São Matheus $(24,15-35)$ referente aos 'falsos prophetas que farão prodigios e coisas espantosas, a ponto de seduzirem os proprios escolhidos'.

'Falsos profetas', sim, porque vem annunciando um paraizo irreal, na terra, para os operarios e os pequenos.

Elles, segundo o mesmo evangelho, fazem effectivamente, nos primeiros instantes de domingo, 'prodigios e coisas espantosas', distribuindo com os proletarios custosas iguarias, vinhos caros, cedulas e moedas de valor.

Mas depois... depois é descoberto o embuste e as mascaras dos hypocritas veem ao chão (O FRACASSO..., 1935, p. 1).

A destruição da edição em que circularia o evangelho de São Matheus (c. 24, v. 15-35), que trata dos "falsos prophetas" e de seus "prodigios e coisas espantosas", teria aqui uma importante carga simbólica. A passagem bíblica foi utilizada didaticamente no retorno do A Ordem, para se referir aos últimos acontecimentos, associando-se, notadamente, os insurretos aos "falsos profetas" e os seus "prodigios e coisas espantosas" a suposta distribuição de "custosas iguarias, vinhos caros, cedulas e moedas de valor" em meio as camadas mais pobres, seduzidas pelo "embuste" comunista. A ação dos comunistas, para o jornal, seria mais uma das formas de que se lançava a "hypocresia" comunista para ludibriar os "pobres operários". Com o fracasso do movimento, continua a matéria: "O paraizo terrestre prometido se esvaiu em fumaça. Adeus tranquilidade. Adeus pão. Adeus terra. Adeus liberdade".

Desqualificar o "proselitismo comunista”, estratégia lançada pelo jornal desde seus primeiros números, seria agora uma tarefa ainda mais urgente, diante da personificação da ameaça e de seus possíveis 
frutos nas camadas populares. A preocupação manifestada, na matéria, nesse sentido, era a possível identificação das camadas pobres, principalmente o operariado, com movimento ao ponto de que acreditassem ser o Governo Popular Revolucionário, de fato, engajado com as causas populares. Não se podia, nesse momento, perder um dos principais argumentos de que os ideais de igualdade dos comunistas eram ilusórios. Para Viana (2011), entretanto, “a agitação nas ruas da cidade era menos uma adesão consciente a um movimento que não tinha consciência de si mesmo e muito mais uma festa pela saída de um governo impopular, pela distribuição de víveres e dinheiro e pela possibilidade de saques" (VIANA, 2011, p. 263).

Quanto aos saques que ocorreram durante os quase quatro dias do chamado Governo Popular Revolucionário, o jornal afirma não terem sido maiores devido à boa índole do povo norte-rio-grandense e ao "lastro ancestral de catholicismo, o fundo de ingênua brandura da nossa gente" que teriam evitado "que mais saques, e principalmente deshonras à familia, se praticassem" (REPRIMIR..., 1935, p. 1). O que se sabe, entretanto, é que a prática de saques foi constante nos dias que seguem a tomada do poder pelos comunistas.

Em meio ao "regozijo geral pela vitoria da legalidade", as narrativas em tono dos levantes foram acompanhadas pelo tom de indignação diante da "audácia comunista", somado, também, ao tom reflexivo em torno das possíveis lições que deveriam ser tiradas da "trágica semana”. Nas edições seguintes, multiplicavam-se, na coluna Graças, agradecimentos "ao triumpho de Religião Católica" diante dos comunistas. Esse recurso se torna interessante para se observar a reação dos leitores diante da insurreição, descrita em sua maioria como "dias de grande aflição" de modo que a derrota comunista seria tratada como uma graça alcançada pelos católicos norte-rio-grandenses, que teriam alcançado, por meio de suas preces em favor da religião católica, a vitória diante do comunismo:

Agredeço ao S. Coração de Jesus e Nossa Senhora as graças alcançadas com a 'Coroa das lagrimas' nos trez dias de aflição por que 
passou o Rio Grande do Norte. Maria do Carmo Pessôa de Mello. (GRAÇAS, 1935a, p. 4).

Ao sagrado coração de Jesus, à Imaculada Conceição a retição do seu rosario e a Santo Antonio - meu coração agradecido pelas graças alcançadas em benefício daqueles para quem implorei o auxilio da Misericordia divina e pelo triumpho da Religião Catholica. Maria Floresta Pessôa da Silva (GRAÇAS, 1935a, p. 4).

A beata Paula Francinete, e a Santa Teresinha, agradece uma graça alcançada, em favor da religião Catholica quando houve nessa cidade um levante comunista. Aura A. Silva. 03-12-935 (GRAÇAS, 1935b, p. 4).

A partir da cobertura ostensiva dos eventos relacionados aos levantes, como as prisões dos implicados, medidas de repressão e as congratulações aos envolvidos na "vitória da legalidade", o jornal procurou endossar, diante da concretização dos temores católicos, as principais demandas do projeto recatolizador, investindo, sobretudo, na necessidade da recristianização da sociedade diante do ataque "a civilização christã". Essa postura se mostrou evidente no editorial de 01 de dezembro, cujo título exclama: Graças a Deus!

A nossa sociedade, mesmo a chamada alta sociedade (e talvez ella principalmente) esquecera, desprezara a lei de Deus. Todos os vícios, toda a triste herança do paganismo, o horror ao sacrificio, o amôr ao fausto, o culto ao corpo, o apego aos principios dissolventes da família, desde o divorcio, a restrição de nascimentos, o aborto, o anti-concepcionismo, até a promiscuidade disfarçada, se praticavam.

E se este era o estado de espírito de nossa burguesia, que differença entre essa mentalidade e a mentalidade communista?

Nenhuma. Ou antes, apenas a de que o convencionalismo burguez procura disfarçar todas essas mazelas e o communismo tem ao menos a coragem de declarar que tudo isso, para ele, é justo, é moral, porque... está de acordo com a sua doutrina, como se principios absolutos de verdade, de Bem, de Moralidade, estivessem 
sujeitos a ser interpretados pela paixão humana (GRAÇAS A DEUS, 1935, p. 1).

No artigo, revela-se a transversalidade entre o discurso anticomunista e o discurso religioso presente, sobretudo, no encadeamento, bastante comum ao catolicismo, que reúne no tripé pecado/castigo/ redenção uma importante estratégia de combate ao inimigo. Nessa esteira, o texto expõe os levantes enquanto "castigo", um "aviso salutar" de Deus, que em sua infinita bondade, mesmo diante dos graves desvios cometidos pela "mentalidade burguesa", "teve piedade do Brasil" diante da "ameaça vermelha". Ao mesmo tempo, para se "emendarem" e se redimirem, restaria aos católicos a volta à prática integral da "philosophia do Evangelho", como forma de restaurar a ordem aviltada e de demarcar o papel da religião nessa restauração:

A bondade de Deus é infinita. Os seus castigos são avisos salutares. Que a tremenda provocação por que passou o Brasil nos sirva de lição. Nós estavamos numa sociedade pagã. E muitos divididos pelo ódio. As lutas partidarias haviam dilacerado a nossa patria, transformando-a em triste arena, onde se degladiavam partidos sem ideias e ideaes, esquecidos dos interesses do Paiz, entretidos principalmente em atassalhar a facção adversa e empregando, para subir ou para não cahir, toda especie de armas.

Enquanto isso, os templos acorriam poucos fieis, o Tabernaculo aguardava em vão que se multiplicassem as visitas e a aranha infernal do comunismo distendia suas teias de monstro, prendendo na sua baba envenenada todos os opprimidos, todos desiludidos que não tinham a graça do consolo da fé e se deixavam arrastar pelos aproveitadores e pelos opportuinistas.

O plano fracassou, dessa vez, graças a Deus. Mas nós ainda não estamos tranquilos. Nós só descansaremos se virmos que os brasileiros aprenderam com a rude lição e estão dispostos a mudar de rumo.

(GRAÇAS A DEUS, 1935, p. 1, grifos nosso). 
O fracasso do plano subversivo seria, portanto, atribuído ao poder divino e deveria deixar uma "lição" aos católicos, cuja carga pedagógica incidiria na integralidade da vida cristã como antídoto a "lepra marxista”. A figura do inimigo e a sua materialização, sob essa perspectiva, seriam essenciais, pois, nesse momento, ela serviria "para fornecer ao povo a consciência de sua unidade, e ao poder que conduz o combate, a legitimidade" (DUTRA, 2012, p. 46). Reforça-se, pois, a assertiva de Baczko (1985, p. 310), de que "quando uma coletividade se sente ameaçada por forças externas, ela operacionaliza o seu dispositivo imaginário com a finalidade de unir, criar um espírito de corpo entre seus membros e possibilitar uma linha de ação conjunta”. Com efeito,

[...] o imaginário social informa acerca da realidade, ao mesmo tempo em que constitui um apelo a acção, um apelo a comportar-se de uma determinada maneira. Esquema de interpretação, mas também de valorização, o dispositivo imaginário suscita a adesão a um sistema de valores e intervém eficazmente nos processos da sua interiorização pelos indivíduos, modelando os comportamentos, capturando as energias e, em caso de necessidade, arrastando os indivíduos para uma ação comum (BACZKO, 1985, p. 311).

O levante de novembro, portanto, "faz convergir para figura do inimigo a possibilidade de pôr termo à dispersão de princípios e às divergências sobre a ameaça ou não de um perigo social" (DUTRA, 2012, p. 44), permitindo o consenso em torno de seu combate. A necessidade de coesão diante da ameaça comunista foi bastante aludida pelos editores do jornal, que, mesmo defendendo a necessidade de união de "todos os orgãos da soberania nacional" em prol da causa anticomunista, procuraram, em diversas oportunidades, demarcar o papel de primazia dos católicos na luta contra o comunismo, haja vista ser a religião, na visão destes, o maior alvo das "machinações geradas nos seios dos que se declaram sequases de doutrinas ímpias, anti-sociaes, anti-nacionaes como o communismo". 
Sob essa perspectiva, "a argumentação religiosa ocupou papel hegemônico nas representações contra-revolucionárias do período" (MOTTA, 2002, p. 214). A Igreja, como nenhuma outra instituição, soube fazer valer essa coesão em torno de um "inimigo comum" para fortalecer as propostas de recristianização da sociedade, cobrando cada vez mais o empenho dos leigos na luta contra os "inimigos da fé". Os editores reforçariam a necessidade de que o povo norte-rio-grandense, de "forte tradição christã", demonstrasse seu "desagravo" à afronta dos comunistas. Nesse momento, verifica-se um esforço em ampliar a participação da sociedade natalense na luta anticomunista, viabilizada sobremaneira pela ação do A Ordem, enquanto porta-voz da Diocese, na veiculação dos posicionamentos católicos.

Em defesa da fé, portanto, as forças católicas norte-rio-grandenses se prestavam a reparar o mal. Com esse intuito, a Confederação Católica masculina e feminina de Natal organizou duas "manifestações públicas de fé" em "reparação aos atentados comunistas", quais sejam uma procissão de "penitência", que percorreria importantes ruas da cidade, e a realização de uma missa em ação de graças "à vitoria da legalidade", celebrada por Dom Marcolino. As cerimônias ocorreriam, respectivamente, nos dias 7 e 8 de dezembro de 1935, com a presença maciça da população e das autoridades locais, marcando a resposta católica aos "atentados contra a civilização christã".

A iniciativa católica foi amplamente divulgada pela imprensa local e teve um espaço privilegiado no órgão de imprensa da Diocese. O A Ordem entendia serem as cerimônias uma prova simbólica do "desagravo" dos católicos natalenses à tentativa de destruição da "civilização christã", "uma pública e grandiosa manifestação de Fé e de repulsa ao materialismo grosseiro", além de oferecerem ao "Deus ultrajado a reparação que se fazia necessaria” (RENDENDO..., 1935, p. 1). Na edição de 03 de dezembro, o jornal já iniciava a divulgação das "paradas de fé" e trazia, em detalhes, o itinerário das cerimônias:

A Confederação Catholica masculina e feminina, sob os auspicios do exmo. Sr. Bispo Diocesano e presidida pelos vigários da Cathedral, Alecrim e Bom Jesus, deliberou promover uma 
grande manifestação publica de fé em reparação do attentado dos communistas à civilização christã e em acção de graças a Deus pela vitoria da legalidade. Contará o desagravo dos catholicos de uma procissão de penitência com a imagem do Bom Jesus das Dores, sabbado 7 de dezembro, às 4 horas da tarde, sahindo o cortejo da Igreja da Ribeira, passando pela Cathedral e recolhendo-se à Matriz do Alecrim. No dia seguinte, domingo, 8 , festa da Imaculada Conceição, haverá às 5 horas da manhã, em frente à Igreja de São Pedro, Missa campal, em acção de graças, celebrada pelo exmo. Sr. Bispo Diocesano, falando ao povo nessa occasião o sabio jesuíta padre Camillo Torrend, presentemente nesta capital. Após a Missa, voltará em procissão à igreja da Ribeira a imagem do Bom Jesus das Dores (AOS CATHOLICOS, 1935, p. 1).

A realização das cerimônias públicas teve, naquele momento, um valor simbólico inestimável para a causa católica. A "reparação ao atentado dos communistas" reafirmaria publicamente a tradição católica norte-rio-grandense ao mesmo tempo em que marcaria o lugar da Igreja e do exército de Cristo Rei no combate anticomunista. Não poderia, portanto, o principal veículo católico deixar de prestigiar a celebração da vitória, que seria, antes de tudo, católica.

A semana que antecedeu os eventos foi marcada, nesse sentido, por uma intensa mobilização. Enquanto o jornal dedicava um espaço privilegiado a divulgação dos dois eventos durante toda semana, as Associações Leigas e Irmandades Religiosas reforçavam a participação de seus membros nas cerimônias. A propaganda dos eventos contou com uma série de medidas que circularam no jornal no sentido de reforçar a mobilização em torno dos eventos:

1 - Intensa propaganda pela A Ordem durante a semana.

2 - Distribuição e afixação de Boletins aos seus fiéis.

3 - Avisos repetidos dos Vigarios e Capellães aos seus fiéis.

4 - Insistir cada presidente de associação junto aos respectivos membros no sentido de nenhum faltar. Trazer o estandarte 
e apresentar-se com as insígnias. As irmandades comparecerão sem opa.

5 - Chamada pelos sinos de todas as Igrejas às 15 horas do sabbado e às 4 do domingo.

6 - Appello às repartições, ao commercio, às fábricas, às officinas, a todos os estabelecimentos de trabalho, afim de cessarem suas actividades às 15 horas do sabbado, e aos que tem interesse na feira do Alecrim a só comparecerem alli, depois de recolhida a procissão, às 7 horas do domingo (AOS CATHOLICOS, 1935, p. 1).

A participação nas paradas de fé seria considerada pelo jornal como um "compromisso de fé" dos católicos norte-rio-grandenses, o que exigiria, por sua vez, a participação maciça da população, daí a intensa mobilização para que toda a cidade parasse para participar das comemorações pela vitória sobre o comunismo. Prova disso, o apelo para que o comércio, as fábricas, as oficinas e todos os estabelecimentos de trabalho encerrassem seus expedientes no horário da celebração, seria mais um dos esforços para que se concentrasse o maior número de pessoas nos eventos. $\mathrm{O}$ apelo foi atendido e no dia 7 de dezembro a Associação Comercial de Natal emitiu a seguinte nota, divulgada no jornal:

A diretoria da Associação Comercial de Natal solicita nos seus consorcios e demais comerciantes desta Capital, a terminarem o expediente do dia 7 do corrente, às 15 horas, afim de que todos possam comparecer à procissão de reparação publica ao attentado ultimamente verificado nesse Estado, à civilização Christã (ASSOCIAÇÃO..., 1935, p. 01).

Foi, portanto, por meio de procissão e missa, que a população natalense glorificou a vitória sobre o perigo vermelho. A Igreja conclamava os fiéis para louvarem e agradecerem a manutenção da ordem na cidade. O Bom Jesus das Dores circularia pelas ruas de Natal em demonstração da luta que fora travada e da necessidade de reunir a população diante de uma causa que perturbava os dirigentes da ordem. 
Ao mesmo tempo em que se rendia graças a Deus e a todas as forças que ajudaram a derrotar os revoltosos, reunia-se a população para alertá-la e orientá-la diante das propostas comunistas.

Significativo exemplo dessa função, a palestra proferida pelo jesuíta Pe. Camilo Torrend, no início da missa campal, publicada pelo A Ordem, revela como essas "concentrações de fé" se mostravam um espaço privilegiado para as batalhas anticomunistas. $\mathrm{Na}$ ocasião, o religioso fez um longo pronunciamento em que se dedicou à reflexão sobre os últimos acontecimentos, descrevendo o inimigo e os seus principais meios de ação, na mesma medida em que cobrou medidas enérgicas em seu combate. Fica claro, portanto, que, em consonância com a cerimônia religiosa fazia-se, também, a tarefa de orientação dos expectadores no sentido de conhecerem e combaterem o inimigo.

Não menos importante e simbólico para o combate comunista seria a procissão de penitência. Em edição de 08 de dezembro de 1935, o jornal assim descreveria a procissão:

Há muito tempo nossa capital não assistia a demonstração de fé tão grandiosa quanto a que hontem presenciamos.

Multidão incalculavel, composta de todas as associações religiosas, masculinas e femininas, escoteiros do mar, alumnas do Orphanato João Maria, povo em geral, accorreu à Igreja do Bom Jesus, de onde partiu a procissão, sendo conduzida até o Alecrim a imagem do Bom Jesus das Dôres. À frente seguiam os estandartes de todas as associações.

Todas as ruas do itinerario, as janellas das casas, estavam repletas de fieis, que em sua maioria se incorporaram ao grandioso prestito.

Durante todo o trajecto foram entoados hymnos sacros e rezado terço.

À porta da Igreja de S. Pedro de Alecrim, acompanhado do monsenhor Alfredo Pegado, encontrava-se o exmo. sr. Bispo d. Marcolino Dantas.

Ao ingressar na Igreja a procissão toda a multidão vibrou em acclamação a Christo Rei (O DESAGRAVO..., 1935, p. 01). 
O cortejo, sua indumentária e a ritualística que marcaria a participação do elemento leigo nas batalhas da fé se tornam interessantes, nesse momento, para se compreender como a causa anticomunista apostou nos elementos do catolicismo militante e na composição apologética que se emprestariam a defesa da fé. A ênfase nos símbolos que materializassem a fé, própria do catolicismo militante, como os estandartes e as insígnias, reforçam a mística do Exército de Cristo Rei, que de modo análogo ao Exército, "onde cada grupo ou corporação se apresenta com seus sinais específicos", ostenta publicamente elementos distintivos de suas associações e movimentos. Assim sendo, os católicos deveriam cerrar as fileiras desse imenso exército em defesa da causa cristã. Na mesma medida, os cânticos entoados, como o famoso "Queremos Deus", versão de Nous voulons Dieu, mediante o qual os católicos franceses reagiram contra o laicismo dominante no país, animava a marcha em ritmo marcial daqueles que estavam dispostos a lutar em nome da fé.

A luta contra o comunismo, portanto, representaria o esforço em salvaguardar o conjunto de princípios, instituições e tradições que compõem a "civilização christã", de modo que as cerimônias não poderiam ser interpretadas como "resultantes da vitória desta ou daquela classe ou facção, mas o triumpho dos principios christão" (CIVILIZAÇÃO..., 1935, p. 01). Essas demonstrações públicas de fé fizeram parte, nesse momento, do esforço de restabelecer o domínio da religião sobre a vida pública, que, por sua vez, se daria com a maior participação da sociedade na luta anticomunista. Resistir à "tempestade comunista", no Rio Grande do Norte, com tudo que fosse disponível à fé cristã, levou a Igreja Católica a uma nova etapa de sua luta contra o comunismo.

Na mesma direção argumentativa de defesa e prontidão para o combate, o editorial de 11de janeiro de 1936, intitulado Reação necessária e assinado por de Pe. Herôncio, investiu no potencial de mobilização do povo "essencialmente christão", pois este teria além do dever "patriota", o dever de zelar pela fé, enquanto cristãos. O artigo, portanto, frisa a necessidade da mobilização popular no combate ao comunismo e na defesa da fé, que, nesse momento, como vimos, 
passavam a ser projetos indissociáveis. Diante deste dever, não seria "lícito ficar indiferente", seria um "crime continuar de braços cruzados"; defendia-se, pois, a reação consciente do povo, que, imbuído dos valores da moral cristã, seria mais poderoso que as "armas da República".

\subsection{Considerações finais}

Em busca do seu lugar na "cruzada anticomunista", a Igreja Católica apostou no alinhamento cada vez mais evidente entre o discurso anticomunista e o projeto recatolizador que, por sua vez, fez da simbiose entre o discurso religioso e o combate ao comunismo, a evidência de que a causa anticomunista deveria ser, acima de tudo, uma causa cristã.

Havia, portanto, um duplo dever a ser cumprido: o de patriota e o de cristão. Amalgamados ao discurso anticomunista veiculado no $A$ Ordem, esses deveres se traduzem no exercício cotidiano de combate ao comunismo e de defesa das tradições cristãs, como elementos que permitiram o fortalecimento das propostas de recatolização, no estado, à medida que se recrudescia a produção do discurso anticomunista. Nesse sentido, em meio à escalada repressiva, evidenciaram-se os esforços para aumentar a "divulgação dos argumentos anticomunistas de base religiosa" (MOTTA, 2002, p. 211), que encontraram no bom combate, o combustível para o fortalecimento da presença católica na sociedade.

Com efeito, à medida que se gestavam as soluções autoritárias no período pós levantes se intensificavam os argumentos em torno da necessidade de se recristianizar a sociedade como barreira mais eficaz ao comunismo, apoiando-se no imaginário anticomunista, engendrado nas páginas do jornal, e na necessidade de coesão das forças católicas diante da ameaça que se presentifica a partir da experiência comunista em terras potiguares. 



\section{REFERÊNCIAS}

AINDA o fracasso do golpe communista. A Ordem. Natal, v. 1, n. 108, p. 1, 3 dez. 1935.

ASSOCIAÇÃO Commercial de Natal. A Ordem. Natal, v. 1, n. 112, p. 1, 7 dez. 1935.

AOS CATHOLICOS. A Ordem. Natal, v. 1, n. 108, p. 1, 3 dez. 1935.

AZZI, R. História da igreja no Brasil: ensaio de interpretação a partir do povo. Petrópolis: Vozes, 2008.

BAZCKO, B. Imaginação social. In: ENCICLOPÉDIA Einaudi. Lisboa: Imprensa Nacional; Casa da Moeda, 1985.

CABRAL, Pe. J. Causas do communismo. A Ordem. Natal, v. 1, n. 111, p. 2, 6 dez. 1935.

CIVILIZAÇÃO cristã e civilização burgueza. A Ordem. Natal, v. 1, n. 112, p. 1, 7 dez. 1935.

COSTA, H. O. A Insurreição comunista de 1935: Natal, o primeiro ato da tragédia. São Paulo: Ensaio; Natal: Cooperativa Cultural Universitária do Rio Grande do Norte, 1995. 
COSTA, H. S. Angustiosa pergunta. A Ordem. Natal, v. 1, n. 113, p. 1, 8 dez. 1935.

DUTRA, E. F. O Ardil totalitário: imaginário político no Brasil dos anos de 1930. 2. ed. Belo Horizonte: UFMG, 2012.

GOMES, P. Do Combate aos extremismos. A Ordem. Natal, v. 1, n. 109, p. 2, 4 dez. 1935a.

GOMES, P. Estamos advertidos. A Ordem. Natal, v. 1, n. 111, p. 1, 6 dez. 1935b.

GOMES, P. Nada de derrotismo. A Ordem. Natal, v. 1, n. 118, p. 1, 14 dez. 1935 c.

GRAÇAS A DEUS! A Ordem. Natal, v. 1, n. 107, p. 1, 1 dez. 1935.

GRAÇAS. A Ordem. Natal, v. 1, n. 108, p. 4, 3 dez. 1935.

MOTTA, R. P. S. Em Guarda contra o "perigo vermelho":

o anticomunismo no Brasil (1917-1964). São Paulo:

Perspectiva, 2002.

O DESAGRAVO dos catholicos. A Ordem. Natal, v. 1, n. 113, p. 1, 8 dez. 1935.

O FRACASSO do golpe communista: a defesa da civilização christã contra a barbaria materialista: regosijo geral pela victoria da legalidade. A Ordem. Natal, v. 1, n. 107, p. 1, 1 dez. 1935.

PATMOS, J. Uma Aurora gotejando sangue. A Ordem. Natal, v. 1, n. 179, p. 1, 29 fev. 1936.

RENDENDO graças a Jesus salvador. A Ordem. Natal, v. 1, n. 114, p. 1, 10 dez. 1935. 
REPRIMIR e previnir. A Ordem. Natal, v. 1, n. 108, p. 1, 3 dez. 1935.

RODEGHERO, C. S. 0 diabo é vermelho: imaginário anticomunista e Igreja Católica no Rio Grande do Sul (1945-1964). 2. ed. Passo Fundo: UPF, 2003.

VIANA, M. A. G. Revolucionários de 1935: sonho e realidade. São Paulo: Expressão Popular, 2011. 